\title{
Safety and Feasibility of Laparoscopic Sleeve Gastrectomy with Loop Duodenal Switch Surgery for Obesity in Indian Patients
}

\author{
Amar Vennapusa ${ }^{1}$, Ramakanth Bhargav Panchangam ${ }^{2}$, Charita Kesara $^{3}$, Tejaswi Chivukula ${ }^{4}$
}

\begin{abstract}
Aim: Laparoscopic sleeve gastrectomy with loop duodenal switch (SLDS) surgery is a loop modification of biliopancreatic diversion with duodenal switch (BPD-DS) aimed at reducing malabsorption without compromising on the efficacy. This study aimed to analyze the safety and feasibility of SLDS surgery in Indians suffering from obesity.

Materials and methods: This was a retrospective study analyzing 169 patients who underwent SLDS surgery between November 2013 and June 2020. The cohort was divided into two subgroups based on the common channel length -2.5 and $\geq 3 \mathrm{~m}$. Weight-loss parameters, diabetes remission, and investigations at 6 months and 1 year follow-up were analyzed in the total cohort and common channel subgroups. The percentage of total weight loss (\%TWL) $\geq 25 \%$ was considered as a successful weight-loss outcome. $\mathrm{HbA} 1 \mathrm{C}<6 \%$ without the need for antidiabetic medications was considered as complete diabetes remission. Safety was analyzed in terms of intraoperative and postoperative complications. Results: Mean preoperative body mass index was $45.39 \pm 7.6 \mathrm{~kg} / \mathrm{m}^{2} .48 .52 \%$ of the patients were suffering from type II diabetes. Mean \%TWL was $30.91 \pm 4.98$ and $41.86 \pm 7.63 \%$ and complete diabetes remission was 81.82 and $89.06 \%$ at 6 months and 1 year follow-up, respectively. The percentage of total weight loss was inversely proportional to the common channel length. Complete diabetes remission was not significantly affected by the common channel length. Serum albumin $<3 \mathrm{gm} / \mathrm{dL}$ was significantly high in patients with a common channel length of $2.5 \mathrm{vs}$ $\geq 3 \mathrm{~m}-25$ vs $4.65 \%$ at 6 months and 40 vs $7.14 \%$ at 1 year follow-up, respectively. Thirty-day mortality was zero.

Conclusion: Sleeve gastrectomy with loop duodenal switch surgery appears to be effective and safe in Indian patients. Malabsorption risk is greatly reduced when the common channel length is $\geq 3 \mathrm{~m}$.

Clinical significance: Sleeve gastrectomy with loop duodenal switch surgery with the common channel length $\geq 3 \mathrm{~m}$ simplifies BPD-DS, gives excellent weight loss and diabetes remission with minimal malabsorption. Restricting the biliopancreatic limb to $\leq 55 \%$ prevents adverse malabsorptive consequences.

Keywords: Bariatric surgery, Biliopancreatic diversion with duodenal switch, Diabetes, Diabetes remission, Metabolic surgery, Obesity, One anastomosis gastric bypass, Single anastomosis duodenoileal bypass with sleeve, Sleeve gastrectomy, Weight loss.

World Journal of Laparoscopic Surgery (2020): 10.5005/jp-journals-10033-1423
\end{abstract}

\section{INTRODUCTION}

Bariatric surgery offers durable weight loss and diabetes remission with minimal complications. Hormonal and physiological alterations are mainly responsible for the metabolic effects after bariatric surgery. ${ }^{1}$ Metabolic outcomes are significantly better after laparoscopic biliopancreatic diversion with duodenal switch (BPD-DS) compared to standard surgeries like laparoscopic Roux-en-Y gastric bypass (RYGB). But nutritional deficiencies are also higher after BPD-DS. ${ }^{2}$ It is not widely performed because of its technical complexity and increased risk of severe malabsorption.

Single anastomosis duodenoileal bypass with sleeve (SADI-S) is a loop modification of duodenal switch with a 2-2.5 m common channel. ${ }^{3}$ It simplifies the procedure and reduces malabsorption to some extent. But even with $2.5 \mathrm{~m}$ common channel malabsorption can be significant in SADI-S. Increasing common channel length to $3 \mathrm{~m}$ can effectively reduce malabsorption. ${ }^{4}$ Several loop duodenal switch (LDS) surgeries were described in the literature with different common channel lengths. ${ }^{5}$

Sleeve gastrectomy with loop duodenal switch (SLDS) is a loop modification of BPD-DS (Fig. 1). ${ }^{6}$ It is technically simple with only one anastomosis, compared to BPD-DS. One main advantage
1,3,4 Department of Bariatric and Metabolic Surgery, Dr Amar Bariatric and Metabolic Center, Hyderabad, Telangana, India

${ }^{2}$ Department of Endocrine and Metabolic Surgery, Endocare Hospital, Vijayawada, Andhra Pradesh, India

Corresponding Author: Amar Vennapusa, Department of Bariatric and Metabolic Surgery, Dr Amar Bariatric and Metabolic Center, Hyderabad, Telangana, India, Phone: +91 96766 75646, e-mail: drVamar@gmail. com

How to cite this article: Vennapusa A, Panchangam RB, Kesara C, et al. Safety and Feasibility of Laparoscopic Sleeve Gastrectomy with Loop Duodenal Switch Surgery for Obesity in Indian Patients. World J Lap Surg 2020;13(3):117-124.

Source of support: Nil

Conflict of interest: None

is common channel length can be tailored according to the individual requirement and depending on the total bowel length. There is no literature available from the Indian subcontinent about this procedure. We analyzed our experience with this surgical technique in Indian patients suffering from obesity to ascertain its safety, feasibility, and efficacy.

(O) The Author(s). 2020 Open Access This article is distributed under the terms of the Creative Commons Attribution 4.0 International License (https://creativecommons. org/licenses/by-nc/4.0/), which permits unrestricted use, distribution, and non-commercial reproduction in any medium, provided you give appropriate credit to the original author(s) and the source, provide a link to the Creative Commons license, and indicate if changes were made. The Creative Commons Public Domain Dedication waiver (http://creativecommons.org/publicdomain/zero/1.0/) applies to the data made available in this article, unless otherwise stated. 


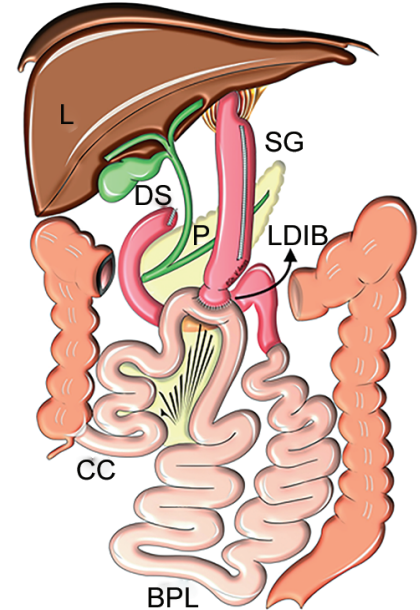

Fig. 1: Schematic diagram of sleeve gastrectomy with loop duodenal switch: BPL (biliopancreatic limb); CC (common channel); DS (duodenal stump); L (liver); P (pancreas); LDIB (loop duodenoileal bypass); SG (sleeve gastrectomy)

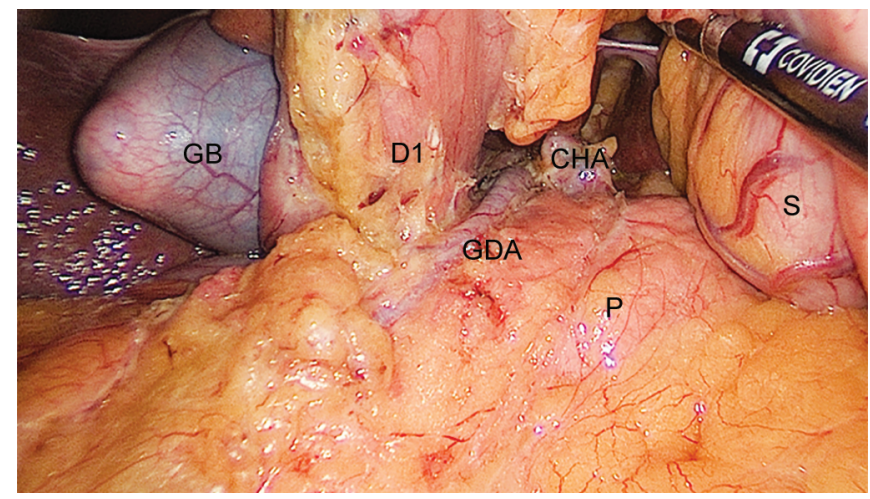

Fig. 2: Operative photograph of the duodenal dissection: $\mathrm{CHA}$ (common hepatic artery); D1 (part of the duodenum); GB (gallbladder); GDA (gastroduodenal artery); P (pancreas); S (stomach)

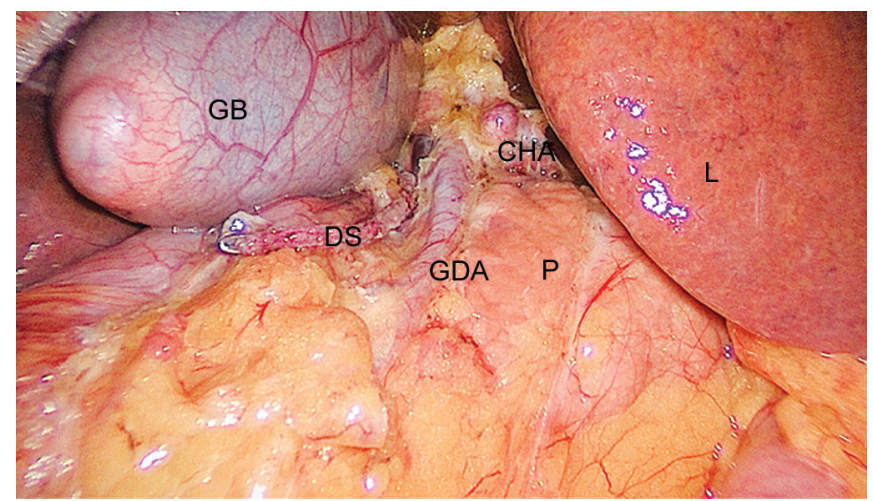

Fig. 4: Operative photograph of the duodenal stump: CHA (common hepatic artery); DS (duodenal stump); GB (gallbladder); GDA (gastroduodenal artery); L (liver); $\mathrm{P}$ (pancreas)

\section{Materials and Methods}

It was a retrospective study of 169 patients who underwent SLDS surgery between November 2013 and June 2020. Patients with body mass index $(\mathrm{BMI}) \geq 30 \mathrm{~kg} / \mathrm{m}^{2}$, those in whom surgery was performed as a primary surgery were included in this study. Those who underwent LDS as a revision surgery were excluded from this study.
Institutional ethics committee approval was obtained and detailed written informed consent was taken from all the participants in this study. Our study complied with the ethical norms proposed by the Helsinki declaration for research involving humans.

\section{Technique}

Four ports were used in all the patients. Devascularization of greater curvature was performed starting opposite to angular incisure. Dissection was continued up to $5 \mathrm{~cm}$ beyond the pylorus and behind the first part of the duodenum until the gastroduodenal artery was identified (Fig. 2). The lesser omental layer over the caudate lobe was divided from behind the stomach to create a window. The right gastric artery (RGA) was divided at its origin using a vessel sealer. This step was a modification compared to the classical SADI-S described by Sánchez-Pernaute et al., ${ }^{7,8}$ This step ensured free mobility of gastric sleeve, pylorus, and the first part of the duodenum as a single unit after the duodenal transection. ${ }^{9}$ A lax sleeve gastrectomy (SG) was performed around a 38 French calibration tube starting $4 \mathrm{~cm}$ proximal to the pylorus. After completion of SG, the duodenum was transected using staplers (Fig. 3 and 4). The divided first part of the duodenum was

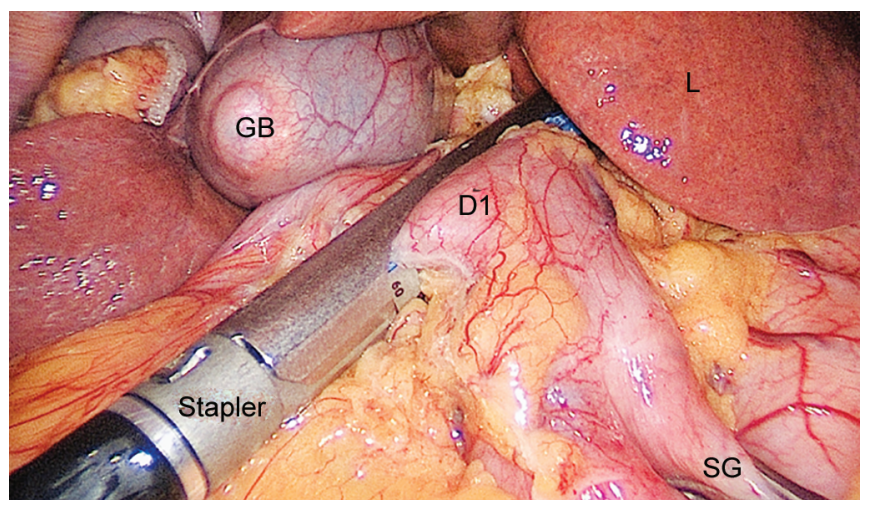

Fig. 3: Operative photograph of the duodenal transection: D1 (part of the duodenum); GB (gallbladder); L (liver); SG (sleeve gastrectomy)

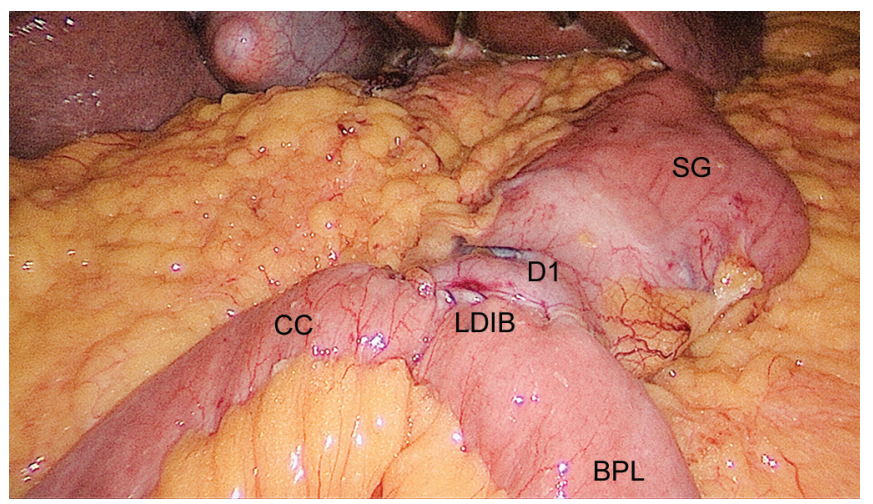

Fig. 5: Operative photograph of loop duodenoileal bypass: BPL (biliopancreatic limb); CC (common channel); D1 (part of the duodenum); LDIB (loop duodenoileal bypass); SG (sleeve gastrectomy)

anastomosed to distal ileum, in the antecolic end to side fashion using 3-0 continuous absorbable sutures in two layers (Fig. 5). In the fixed common channel (FCC) variant of SLDS surgery, the common channel length was fixed at $2.5,3$, or $3.5 \mathrm{~m}$ proximal to the ileocecal junction. In the fixed ratio bypass (FRB) variant of SLDS surgery, a fixed percentage of the jejunoileal length was bypassed. 
Patients were discharged on the second postoperative day. Contrast X-ray and an abdominal sonography were performed 1 week and 1 month postoperatively to screen for leak and bleeding. Patients were prescribed lifelong bariatric multivitamin, mineral supplements, and ursodeoxycholic acid for 18 months.

Weight and BMI were documented at 6 months and 1 year follow-up and percentage of excess weight loss (\%EWL) with BMI reference point of $25 \mathrm{~kg} / \mathrm{m}^{2}$ and percentage of total weight loss (\%TWL) were calculated. The percentage of total weight loss $\geq 25 \%$ was considered as a successful weight-loss outcome. The percentage of excess weight loss $\geq 50 \%$ was taken as an alternative reference point to define a successful outcome. Complete diabetes remission was defined as $\mathrm{HbA} 1 \mathrm{C}<6 \%$ with no antidiabetic medications needed for glycemic control. Partial diabetes remission was defined as $\mathrm{HbA} 1 \mathrm{C} \geq 6 \%$ but $<6.5 \%$ in the absence of antidiabetic medications. Diabetes improvement was defined as a statistically significant reduction in $\mathrm{HbA} 1 \mathrm{C}$ not meeting the criteria for complete or partial remission or decrease in requirement for antidiabetic medications. Differences in \%TWL, \%EWL, and $\mathrm{HbA} 1 \mathrm{C}$ at 6 months and 1 year follow-up in subgroups based on the common channel were calculated using independent samples t test. The effect of common channel length on the weight-loss parameters was analyzed using simple linear regression and multiple regression analysis. The effect of common channel length on the weight-loss success rates and diabetes remission rates was calculated using logistic regression analysis. IBM SPSS version 26 (IBM Corp., Armonk, NY, USA) was used for statistical analysis. $p$ value of $<0.05$ was considered significant in various statistical tests.

Major complications, such as, internal bleeding and leak, were documented. Nutritional parameters including total protein and serum albumin at 6 months and 1 year follow-up were documented.

\section{Results}

A total of 171 patients underwent SLDS surgery between November 2013 and June 2020. One hundred and sixty-nine patients who met the inclusion criteria were analyzed. The mean age was $40.53 \pm 10.07$ years (16-68). Male:female ratio was $87: 82$. BMI of $24.85 \%(42 / 169)$ patients was $\geq 50 \mathrm{~kg} / \mathrm{m}^{2}$. 48.52\% (82/169) patients were suffering from type Il diabetes. $30.18 \%$ (51/169) patients had prediabetes. The average common channel length was $3.33 \pm 0.41$ (2.5-4.32) m. A fixed common channel variant was performed in 144 patients (the common channel was fixed at 2.5, 3, and $3.5 \mathrm{~m}$ in 26, 16, and 102 patients, respectively). Fixed ratio bypass variant was performed in 25 patients (the common channel length was 55\% in 1, 50\% in $13,45 \%$ in 8 , and $40 \%$ in 3 patients). $98.7 \%$ (152/154) and $91.24 \%$ $(125 / 137)$ patients were available at the 6 months and 1 year follow-up, respectively.

Weight and BMI parameters of patients at different time intervals are summarized in Table 1. Overall weight and BMI were significantly less at 6 months and 1 year follow-up compared to preoperative values (Table 1). The percentage of total weight loss and \%EWL with BMI reference point of $25 \mathrm{~kg} / \mathrm{m}^{2}$ in the total cohort and common channel subgroups at 6 months and 1 year follow-up after surgery are summarized in Table 1 . Independent samples t test showed significantly more \%TWL in patients with $2.5 \mathrm{~m}$ common channel compared to those with $\geq 3 \mathrm{~m}$. Simple linear regression and multiple regression analysis showed that \%TWL was inversely proportional to the common channel length at 6 months and 1 year follow-up. The percentage of excess weight loss was similar between the subgroups and the common channel length effect on \%EWL was found to be insignificant (Table 1). The weight-loss success rate was $91.45 \%(139 / 152)$ and $99.2 \%(124 / 125)$ at 6 months and 1 year follow-up when $\%$ TWL $\geq 25 \%$ was taken as a reference point. These values were $97.37 \%(148 / 152)$ and $100 \%(125 / 125)$ at 6 months and 1 year follow-up when $\% E W L \geq 50 \%$ was taken as a reference point. There was no significant difference in the weightloss success rates between the common channel subgroups.

$\mathrm{HbA} 1 \mathrm{C}$ in the total cohort and common channel subgroups at 6 months and 1 year follow-up are summarized in Table 2. HbA1C was significantly low at 6 months and 1 year follow-up compared to preoperative values. There was no significant difference in $\mathrm{HbA1C}$ between the common channel subgroups at 6 months follow-up. But $\mathrm{HbA1C}$ was significantly low in patients with common channel length $2.5 \mathrm{vs} \geq 3 \mathrm{~m}$ at 1 year follow-up.

Complete diabetes remission, partial diabetes remission, and diabetes improvement with $\mathrm{HbA} 1 \mathrm{C}<6 \%$ reference point in the total cohort and common channel subgroups at 6 months and 1 year follow-up are summarized in Table 2 . There was no significant difference in the percentage of complete diabetes remission between common channel subgroups. There were no symptoms of hypoglycemia or dumping syndrome in any of our patients. Responses of different comorbid conditions to SLDS surgery are summarized in Table 3.

Indicators of nutritional status are detailed in Table 4. Proteinenergy malnutrition with serum albumin levels $<3 \mathrm{gm} / \mathrm{dL}$ was significantly high in patients with a common channel length of $2.5 \mathrm{vs}$ $\geq 3 \mathrm{~m}-25$ vs $4.65 \%$ at 6 months and 40 vs $7.14 \%$ at 1 year follow-up, respectively. In patients with common channel length $\geq 3 \mathrm{~m}$, all the patients with serum albumin $<3 \mathrm{gm} / \mathrm{dL}$ at 6 months and 1 year follow-up had biliopancreatic limb length of $>55 \%$. Poor nutritional intake coupled with malabsorption was responsible for proteinenergy malnutrition in these patients. Marked hypoalbuminemia $(<2.5 \mathrm{~g} / \mathrm{dL}$ ) with clinical manifestations in eight patients ( 5 and 3 from $2.5 \mathrm{~m}$ and $\geq 3 \mathrm{~m}$ common channel subgroups, respectively) was corrected using intravenous amino acid injections, a high protein diet, and regular exercises. Hypoalbuminemia improved in all these patients except in two of them, one from each subgroup, who lost life $>1$ year after surgery. All patients who developed mild vitamin and mineral deficiencies responded well to oral supplements.

Concomitant cholecystectomy was performed in 10 patients, adhesiolysis in 21, and different types of hernia repairs in 11 patients. The mean duration of surgery was 191.49 minutes. Intraoperative injury to RGA with $250 \mathrm{~mL}$ blood loss occurred in one patient. Bleeding was controlled with a vessel sealer. 1.18\% (2/169) patients developed postoperative bleeding on the first postoperative day, requiring diagnostic laparoscopy and lavage. All these patients recovered without any adverse postoperative events. One patient developed a localized leak 10 days after surgery but recovered with conservative treatment. 28.18 and $27.08 \%$ patients complained of diarrhea, 80 and $66.67 \%$ steatorrhea, 74.55 and $65.63 \%$ foulsmelling gas, and 11.82 and $8.33 \%$ incontinence at 6 months and 1 year follow-up after surgery, respectively, when their diet contained oil, spice, or chilly. 4.55 and $3.13 \%$ of patients complained of constipation at 6 months and 1 year follow-up after surgery, respectively. Thirty-day mortality was zero. None of the patients had gastroesophageal reflux, marginal ulcers, or internal herniation.

\section{Discussion}

Laparoscopic SG has gained a lot of popularity and became the most commonly performed surgery worldwide. ${ }^{10}$ Its technical simplicity, 
Safety and Feasibility of Sleeve Gastrectomy with Loop Duodenal Switch

Table 1: Weight parameters

\begin{tabular}{|c|c|c|c|c|c|c|c|}
\hline \multirow{2}{*}{ Parameter } & & \multicolumn{2}{|c|}{ Preoperative } & \multicolumn{2}{|c|}{6 months follow-up } & \multicolumn{2}{|r|}{1 year follow-up } \\
\hline & & $N$ & Mean $\pm S D$ & $N$ & Mean $\pm S D$ & $N$ & Mean $\pm S D$ \\
\hline Weight (kg) & & 169 & $125.46 \pm 24.7$ & 152 & $85.72 \pm 15.68$ & 125 & $71.23 \pm 11.83$ \\
\hline${ }^{\mathrm{a}}$ Significance & & & & & $p<0.001(\mathrm{~A}-\mathrm{B})$ & & $p<0.001(\mathrm{~A}-\mathrm{C})$ \\
\hline BMI $\left(\mathrm{kg} / \mathrm{m}^{2}\right)$ & & 169 & $45.39 \pm 7.6$ & 152 & $31.12 \pm 4.77$ & 125 & $26.01 \pm 3.59$ \\
\hline${ }^{a}$ Significance & & & & & $p<0.001(\mathrm{~A}-\mathrm{B})$ & & $p<0.001(\mathrm{~A}-\mathrm{C})$ \\
\hline \multicolumn{8}{|l|}{$\%$ Excess weight loss } \\
\hline Overall & & - & - & 152 & $74.53 \pm 19.21$ & 125 & $99.24 \pm 20.62$ \\
\hline asignificance & & & & & & & $p<0.001(\mathrm{~B}-\mathrm{C})$ \\
\hline \multirow[t]{2}{*}{ Common channel length } & $2.5 \mathrm{~m}$ & - & - & 26 & $70.9 \pm 8.45$ & 23 & $101.87 \pm 8.45$ \\
\hline & $\geq 3 \mathrm{~m}$ & - & - & 126 & $75.28 \pm 20.69$ & 102 & $98.64 \pm 22.46$ \\
\hline${ }^{\mathrm{b}}$ Significance & & & & & $p=0.081$ & & $p=0.258$ \\
\hline 'Simple linear regression & & & & & $p=0.78(\mathrm{~B}=0.011)$ & & $p=0.272(\mathrm{~B}=-0.051)$ \\
\hline \multicolumn{8}{|l|}{$\%$ Total weight loss } \\
\hline Overall & & - & - & 152 & $30.91 \pm 4.98$ & 125 & $41.86 \pm 7.63$ \\
\hline${ }^{\mathrm{a} S}$ Significance & & & & & & & $p<0.001(\mathrm{~A}-\mathrm{C})$ \\
\hline \multirow[t]{2}{*}{ Common channel length } & $2.5 \mathrm{~m}$ & - & - & 26 & $35.98 \pm 5.49$ & 23 & $51.23 \pm 6.55$ \\
\hline & $\geq 3 \mathrm{~m}$ & - & - & 126 & $29.87 \pm 4.18$ & 102 & $39.75 \pm 6.13$ \\
\hline${ }^{\mathrm{b}}$ Significance & & & & & $p<0.001$ & & $p<0.001$ \\
\hline 'Simple linear regression & & & & & $p<0.001(\mathrm{~B}=-0.052)$ & & $p<0.001(\mathrm{~B}=-0.087)$ \\
\hline $\begin{array}{l}{ }^{\mathrm{C}} \text { Multiple regression } \\
\text { analysis }\end{array}$ & & & & & $p<0.001(\mathrm{~B}=-0.045)$ & & $p<0.001(B=-0.068)$ \\
\hline
\end{tabular}

apaired samples $t$ test

${ }^{b}$ Independent samples $t$ test

'Significance when the common channel length was taken as an independent variable

easy reproducibility, and low complication profile made it the most popular bariatric surgery. But its main drawback is increased risk of long-term weight regain and recurrence of comorbid conditions. ${ }^{11}$ Several of these patients require revision surgery. ${ }^{12}$

Roux-en-Y gastric bypass and its loop variation, one anastomosis gastric bypass (OAGB), lead to more durable weight loss and diabetes remission. ${ }^{13-15}$ Roux-en-Y gastric bypass has limitations, such as, inability to monitor remnant stomach endoscopically, increased risk of calcium, and iron deficiencies due to complete duodenal bypass, dumping due to bypass of the pylorus, lack of endoscopic access to the biliary tract, marginal ulcer risk due to unopposed exposure of the jejunum to gastric juice and internal hernias due to mesenteric defects. ${ }^{16}$ One anastomosis gastric bypass became more popular because of technical simplicity and an easy learning curve. ${ }^{17}$ It can address marginal ulcers and internal hernias to some extent but other problems persist. The risk of calcium and iron deficiencies is relatively more in OAGB. ${ }^{18}$ Even though these complications are outweighed by their advantages, novel surgeries to obviate those problems were attempted. ${ }^{19}$

BPD-DS is the most effective surgery in terms of the durability of weight loss and diabetes remission. ${ }^{20}$ Preservation of the pylorus and the first part of the duodenum can address calcium and iron deficiencies to some extent but extensive intestinal bypass leaving only $1 \mathrm{~m}$ for absorption, increases the risk of severe protein-energy malnutrition, severe nutritional deficiencies, and renal stones. ${ }^{21}$

To reduce malabsorption and simplify the BPD-DS procedure, Sánchez-Pernaute et al. proposed a loop modification of the duodenal switch in 2007, by anastomosing the duodenum directly to a loop of ileum $2 \mathrm{~m}$ proximal to the ileocecal junction. ${ }^{7}$ Increasing common channel from $1 \mathrm{~m}$ in BPD-DS to $2 \mathrm{~m}$ in SADI-S addressed malabsorption to some extent. But it was still a concern. To address this malabsorption issue, later they increased the common channel from 2 to $2.5 \mathrm{~m}^{22}$ Mitzman et al. proposed increasing common channel to $>2.5 \mathrm{~m}$ in LDS surgeries. They published their experience with $3 \mathrm{~m}$ common channels in LDS surgeries which showed excellent metabolic outcomes and reduced risk of malabsorption. ${ }^{23}$ Theoretical benefits of LDS surgeries over BPD-DS include a reduced risk of complications with similar weight loss and health benefits. ${ }^{5}$

Sleeve gastrectomy with loop duodenal switch is a loop modification of BPD-DS. The advantage of LDS surgery is the scope of adjusting limb lengths to suit individual requirements. Our results showed that SLDS surgery was a very effective surgery to induce significant weight loss. Moon et al. showed \%TWL of $23.1 \%$ at 6 months and $37.1 \%$ at 12 months after LDS surgeries. The percentage of excess BMI loss was $41.9 \%$ at 6 months and $68.1 \%$ at 12 months follow-up. ${ }^{24}$ Cottam et al. showed that there was a significant reduction of BMI from baseline $46.8 \pm 5.8$ to $29.8 \pm 4.4 \mathrm{~kg} / \mathrm{m}^{2}$ at 1 year follow-up after LDS surgeries. ${ }^{25}$ Weight-loss response in our patients was similar to the results shown in these studies. Studies have shown similar \%TWL after LDS surgeries and BPD-DS. ${ }^{4,24}$ In our patients, increasing common channels from 2.5 to $\geq 3 \mathrm{~m}$, reduced efficacy of surgery in terms of weight-loss response but the success rate remained unaltered. So, our results showed that the common channel can be increased from 2.5 to $\geq 3 \mathrm{~m}$ without altering the efficacy of surgery.

Our results indicate that SLDS surgery is a very powerful metabolic surgery for diabetes remission. Cottam et al. showed diabetes remission of $96.3 \%$ at a 1 year follow-up after the single anastomosis duodenal switch (SADS). ${ }^{25}$ Diabetes remission was 


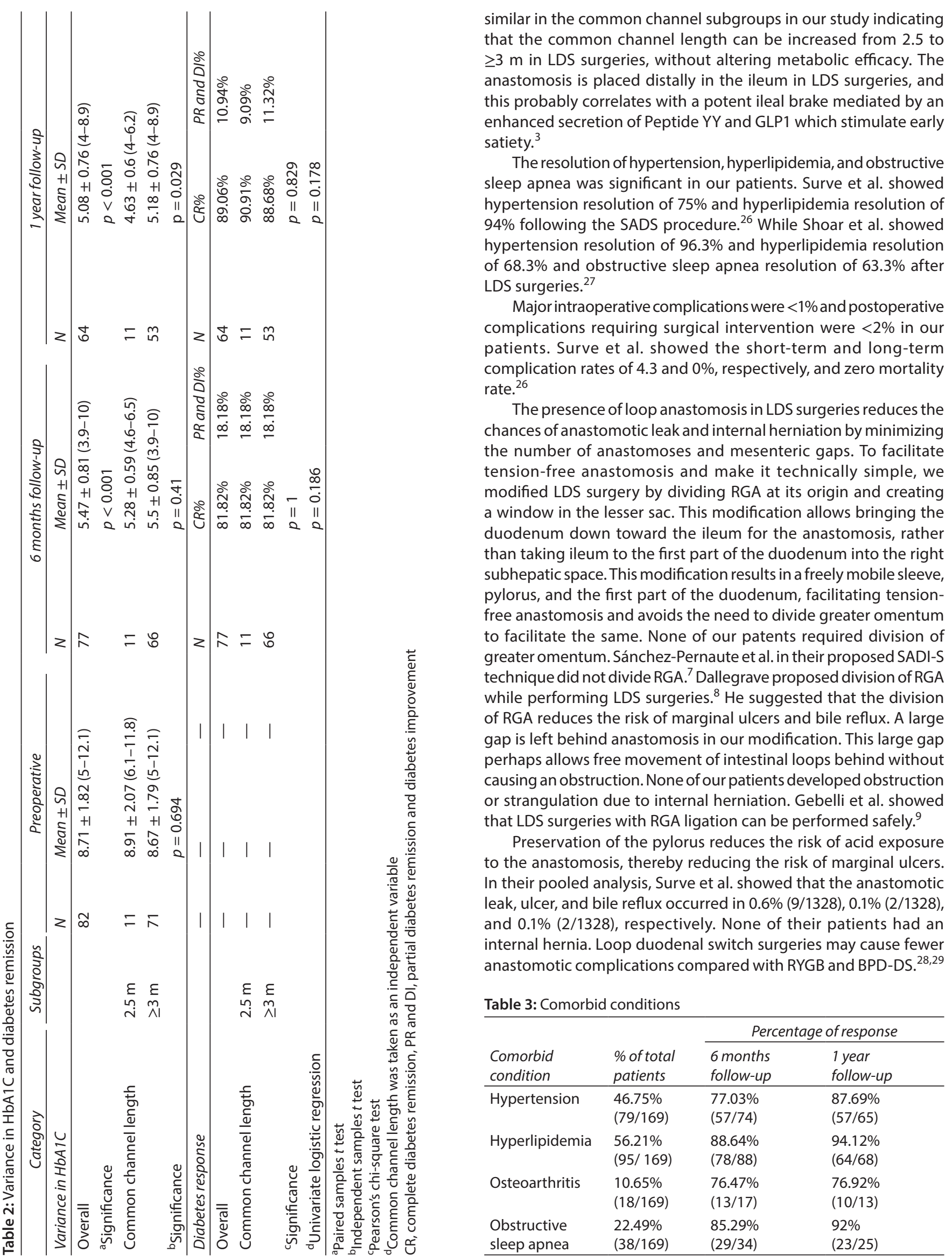




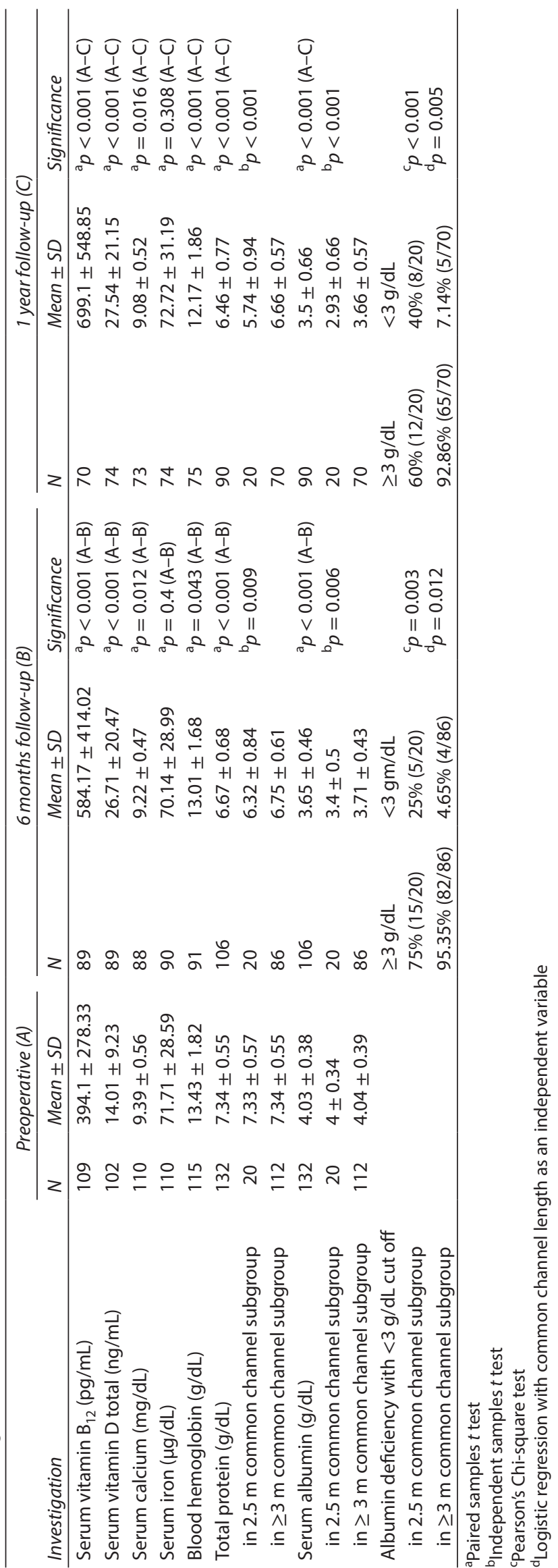

None of our patients had an anastomotic leak or marginal ulcers. None of our patients required readmission because of major postoperative complications. Patients who underwent BPD-DS or LDS surgeries have a unique risk of duodenal stump leakage, though incidence is very low. The superior quality of staplers and the presence of anastomosis farther away from the duodenal stump probably reduce risk of stump leak. Nelson et al. reported a duodenal stump leak of $1.45 \%(1 / 69) .{ }^{30}$ None of our patients had duodenal stump leakage.

Since all of our patients were kept on regular vitamin and mineral supplements, we noticed significantly increased serum vitamin D total and B12 levels at 6 months and 1 year follow-up. Moon et al. noted low levels of serum vitamin D at 6 and 12 months following SADS. ${ }^{24}$ Shoar et al. reported that serum vitamin A, selenium, and iron deficiency were the most common nutritional deficiencies after LDS surgeries with $3 \mathrm{~m}$ common channel. ${ }^{27}$ Surve et al., in the pooled data analysis of SADS surgeries, did not find any statistically significant difference between most of the pre- and postoperative nutritional data. ${ }^{28}$

In our patients, the extent of hypoalbuminemia significantly reduced from 40 to $7.14 \%$, when the common channel was increased from 2.5 to $\geq 3 \mathrm{~m}$. Sánchez-Pernaute et al. showed low levels of protein in $34 \%$ of patients and albumin in $13.7 \%$ of patients after SADI-S with 2 to $2.5 \mathrm{~m}$ common channel. ${ }^{22}$ Enochs reported protein and albumin deficiency in 7.6 and $3.1 \%$ of the SADS patients with $3 \mathrm{~m}$ common channels, respectively, at 1 year follow-up. ${ }^{31}$ Surve et al. showed that 6.6 and $6.2 \%$ of the patients had abnormal protein and albumin levels, respectively, after LDS surgeries with $3 \mathrm{~m}$ common channel. ${ }^{26}$ Our study showed that Indian patients are at significantly higher risk of protein deficiency after LDS surgeries when the common channel was 2.5 $\mathrm{m}$ compared to those with $\geq 3 \mathrm{~m}$. Since all the patients who had serum albumin levels $<3 \mathrm{gm} / \mathrm{dL}$ had biliopancreatic limb length of $>55 \%$, we recommend measuring total jejunoileal length in all the patients and restrict biliopancreatic limb length to $\leq 55 \%$, to prevent protein malnutrition.

Increasing biliopancreatic limb beyond $2 \mathrm{~m}$ in RYGB or OAGB increases the risk of protein-energy malnutrition, nutrient malabsorption, and diarrhea. ${ }^{32}$ Biliopancreatic limb length is directly proportional to the efficacy of surgery. ${ }^{33}$ Preservation of pylorus and the first part of the duodenum perhaps play a role in reducing malabsorption in LDS surgeries. Pylorus controls gastric emptying, allowing a greater length of the intestine to be bypassed without malabsorptive consequences. ${ }^{33}$ Preservation of pylorus reduces the risk of dumping syndrome. This is again related to the control of gastric emptying. ${ }^{23}$ Pylorus also prevents the reflux of ileal contents into the stomach. ${ }^{33}$ With our technical modification, once anastomosis is completed - sleeve, pylorus, the first part of the duodenum, and anastomosis lie in a straight vertical line. This theoretically reduces the risk of reflux into the esophagus as well as reflux of ileal contents into the sleeve. We presume this adds extra protection against reflux in addition to the pylorus. None of our patients had postoperative symptoms of esophageal reflux.

One disadvantage of LDS surgeries is the loss of endoscopic access to the biliary tract. If anyone develops cholangitis or choledocholithiasis, the only option is laparoscopic common bile duct exploration. To reduce the incidence of cholelithiasis, all our patients were kept on prophylactic ursodeoxycholic acid. Studies showed that fewer complications like chronic diarrhea, smelly stools, and flatulence were reported in LDS surgeries with 
3 m common channel compared to BPD-DS. ${ }^{4,29}$ In our study, we observed that these bowel problems were triggered when there was oil, spice, or chilly in the food. So, our patients were advised to avoid these items after surgery.

\section{Conclusion}

This study showed that SLDS surgery is safe and feasible. Nutritional complications significantly come down when the common channel is increased to $\geq 3 \mathrm{~m}$ without compromising on the metabolic efficacy of the procedure. More studies with long-term follow-up are needed to determine the ideal common channel length to standardize this promising procedure.

\section{Clinical Significance}

Sleeve gastrectomy with loop duodenal switch surgery with common channel length $\geq 3 \mathrm{~m}$ simplifies BPD-DS, gives excellent weight loss and diabetes remission with minimal malabsorption. Restricting biliopancreatic limb to $\leq 55 \%$ prevents adverse malabsorptive consequences.

\section{Disclaimer}

We hereby declare that there are no hidden conflicts of interests either financial or plagiarism related or any other related to the clinical content and work of this manuscript.

\section{References}

1. Tam CS, Berthoud HR, Bueter M, et al. Could the mechanisms of bariatric surgery hold the key for novel therapies? report from a Pennington scientific symposium. Obes Rev 2011;12(11):984-994. DOI: 10.1111/j.1467-789X.2011.00902.x Epub 2011 Jul 6.

2. Schauer PR, Bhatt DL, Kirwan JP, et al. Bariatric surgery vs intensive medical therapy for diabetes-5 year outcomes. N Engl J Med 2017;376(7):641-651. DOI: 10.1056/NEJMoa1600869.

3. Sánchez-Pernaute A, Herrera MA, Pérez-Aguirre ME, et al. Single anastomosis duodeno-ileal bypass with sleeve gastrectomy (SADI-S). One to three-year follow-up. Obes Surg 2010;20(12):1720-1726. DOI: 10.1007/s11695-010-0247-3.

4. Cottam A, Cottam D, Portenier D, et al. A matched cohort analysis of stomach intestinal pylorus saving (SIPS) surgery vs biliopancreatic diversion with duodenal switch with two-year follow-up. Obes Surg 2017;27(2):454-461. DOI: 10.1007/s11695-016-2341-7.

5. Brown WA, Ooi G, Higa K, et al. Single anastomosis duodenal-ileal bypass with sleeve gastrectomy/one anastomosis duodenal switch (SADI-S/OADS) IFSO Position statement. Obes Surg 2018;28(5):12071216. DOI: $10.1007 / \mathrm{s} 11695-018-3201-4$.

6. Cottam A, Cottam D, Roslin M, et al. A matched cohort analysis of sleeve gastrectomy with and without $300 \mathrm{~cm}$ loop duodenal switch with 18-month follow-up. Obes Surg 2016;26:2363-2369. DOI: 10.1007/s11695-016-2133-0.

7. Sánchez-Pernaute A, Rubio Herrera MA, Pérez-Aguirre $E$, et al. Proximal duodenal-ileal end-to-side bypass with sleeve gastrectomy: proposed technique. Obes Surg 2007;17(12):1614-1618. DOI: 10.1007/ s11695-007-9287-8.

8. Dallegrave Marchesini JC. End-to-side duodeno-jejunostomy with half-and-half biliopancreatic limb for the treatment of type ll diabetes: a proposal for a SIMPLER technique. Obes Surg 2007;17(1):138-139. DOI: 10.1007/s11695-007-9019-0.

9. Gebelli JP, Gordejuela AG, Ramos AC, et al. SADI-S with right gastric artery ligation: technical systematization and early results. Arq Bras Cir Dig 2016;29(Suppl 1):85-90. DOI: 10.1590/0102-6720201600s10021.

10. Angrisani $L$, Santonicola $A$, lovino $P$, et al. Bariatric surgery and endoluminal procedures: IFSO worldwide survey 2014. Obes Surg 2017;27(9):2279-2289. DOI: 10.1007/s11695-017-2666-x.
11. Lauti $M$, Kularatna $M$, Hill AG, et al. Weight regain following sleeve gastrectomy—a systematic review. Obes Surg 2016;26(6):1326. DOI: 10.1007/s11695-016-2152-x.

12. Dijkhorst PJ, Boerboom AB, Janssen IMC, et al. Failed sleeve gastrectomy: single anastomosis duodenoileal bypass or rouxen-Y gastric bypass? A multicenter cohort study. Obes Surg 2018;28(12):3834-3842. DOI: 10.1007/s11695-018-3429-z.

13. Zhao H, Jiao L. Comparative analysis for the effect of roux-en-Y gastric bypass vs sleeve gastrectomy in patients with morbid obesity: evidence from 11 randomized clinical trials (meta-analysis). Int J Surg 2019;72:216-223. DOI: 10.1016/j.ijsu.2019.11.013. Epub 2019 Nov 20.

14. Lee WJ, Chong K, Aung L, et al. Metabolic surgery for diabetes treatment: sleeve gastrectomy or gastric bypass? World J Surg 2017;41(1):216-223. DOI: 10.1007/s00268-016-3690-z.

15. Kansou G, Lechaux D, Delarue J, et al. Laparoscopic sleeve gastrectomy vs laparoscopic mini gastric bypass: one year outcomes. Int J Surg 2016;33(Pt A):18-22. DOI: 10.1016/j.ijsu.2016.07.051 Epub 2016 Jul 22.

16. Magouliotis DE, Tasiopoulou VS, Tzovaras G. One anastomosis gastric bypass vs roux-en-Y gastric bypass for morbid Obesity: an updated meta-analysis. Obes Surg 2019;29(9):2721-2730. DOI: 10.1007/s11695019-04005-0.

17. Solouki A, Kermansaravi M, Davarpanah Jazi AH, et al. Oneanastomosis gastric bypass as an alternative procedure of choice in morbidly obese patients. J Res Med Sci. 2018 23:84. DOI: 10.4103/ jrms.JRMS_386_18.eCollection 2018.

18. Kessler Y, Adelson D, Mardy-Tilbor L, et al. Nutritional status following one anastomosis gastric bypass. Clin Nutr 2019;39(2):599-605. DOI: 10.1016/j.clnu.2019.03.008 [Epub ahead of print].

19. Martini F, Paolino L, Marzano E, et al. Single-anastomosis pyloruspreserving Bariatric procedures: review of the literature. Obes Surg 2016;26(10):2503-2515. DOI: 10.1007/s11695-016-2310-1.

20. Copăescu C. Laparoscopic biliopancreatic diversion with duodenal switch-the most effective operation for type II diabetes Mellitus. How I do it? Chirurgia (Bucur) 2018;113(5):704-711. DOI: 10.21614/ chirurgia.113.5.704.

21. Homan J, Betzel B, Aarts EO, et al. Vitamin and mineral deficiencies after biliopancreatic diversion and biliopancreatic diversion with duodenal switch - the rule rather than the exception. Obes Surg 2015;25(9):1626-1632. DOI: 10.1007/s11695-015-1570-5.

22. Sánchez-Pernaute A, Rubio MÁ, Cabrerizo L, et al. Single-anastomosis duodenoileal bypass with sleeve gastrectomy (SADI-S) for obese diabetic patients. Surg Obes Relat Dis 2015;11(5):1092-1098. DOI: 10.1016/j.soard.2015.01.024Epub 2015 Feb 7.

23. Mitzman B, Cottam D, Goriparthi R, et al. Stomach intestinal pylorus sparing (SIPS) surgery for morbid Obesity: retrospective analyses of our preliminary experience. Obes Surg 2016;26(9):2098-2104. DOI: 10.1007/s11695-016-2077-4.

24. Moon RC, Kirkpatrick V, Gaskins L, et al. Safety and Effectiveness of single-Vs double-anastomosis duodenal switch at a single institution. Surg Obes Relat Dis 2019;15(2):245-252. DOI: 10.1016/j. soard.2018.11.004. Epub 2018 Nov 14.

25. Cottam D, Roslin M, Enochs $P$, et al. Single anastomosis duodenal switch: 1 year outcomes. Obes Surg 2020;30(4):1506-1514. DOI: 10.1007/s11695-019-04352-y.

26. Surve A, Rao R, Cottam D, et al. Early outcomes of primary SADI-S: an Australian experience. Obesity Surgery 2020;30(4):1429-1436. DOI: 10.1007/s11695-019-04312-6.

27. Shoar S, Poliakin L, Rubenstein R, et al. Single anastomosis duodeno-ileal switch (SADIS): a systematic review of efficacy and safety. Obes Surg 2018;28(1):104-113. DOI: 10.1007/s11695-0172838-8.

28. Surve A, Cottam D, Sanchez-Pernaute A, et al. The incidence of complications associated with loop duodeno-ileostomy after singleanastomosis duodenal switch procedures among 1328 patients: a multicenter experience. Surg Obes Relat Dis 2018;14(5):594-601. DOI: 10.1016/j.soard.2018.01.020 Epub 2018 Feb 2. 
29. Surve A, Zaveri $H$, Cottam D, et al. A retrospective comparison of biliopancreatic diversion with duodenal switch with single anastomosis duodenal switch (SIPS-stomach intestinal pylorus sparing surgery) at a single institution with two year follow-up. Surg Obes Relat Dis 2017;13(3):415-422. DOI: 10.1016/j.soard.2016.11.020Epub 2016 Dec 2.

30. Nelson L, Moon RC, Teixeira AF, et al. Safety and effectiveness of single anastomosis duodenal switch procedure: preliminary result from A single institution. Arq Bras Cir Dig 2016;29(Suppl 1):80-84. DOI: 10.1590/0102-6720201600s10020.

31. Enochs P. The laparoscopic stomach, intestinal and pylorus sparing (sips) procedure; a single center analysis of our first 100 patients.
Surg Obes Rel Dis 2015;11(6):S165-S166. DOI: 10.1016/j.soard.2015. 08.261.

32. Mahawar KK, Parmar C, Graham Y. One anastomosis gastric bypass: key technical features, and prevention and management of procedure-specific complications. Minerva Chir 2019;74(2): 126-136. DOI: 10.23736/S0026-4733.18.07844-6. Epub 2018 Jul 18.

33. Roslin M, Tugertimur B, Zarabi S, et al. Is there a better design for a Bariatric procedure? the case for a single anastomosis duodenal switch. Obes Surg 2018;28(12):4077-4086. DOI: 10.1007/s11695-0183535-y. 